\title{
Mission Life Thermal Analysis and Environment Correlation for the Lunar Reconnaissance Orbiter
}

\author{
Matthew B. Garrison, Hume Peabody \\ NASA Goddard Space Flight Center, Greenbelt MD 20771 \\ and \\ Sharon Peabody \\ Edge Space Systems, Glenelg, MD 21737
}

\begin{abstract}
Standard thermal analysis practices include stacking worst-case conditions including environmental heat loads, thermo-optical properties and orbital beta angles. This results in the design being driven by a few bounding thermal cases, although those cases may only represent a very small portion of the actual mission life. The NASA Goddard Space Flight Center Thermal Branch developed a procedure to predict the flight temperatures over the entire mission life, assuming a known beta angle progression, variation in the thermal environment, and a degradation rate in the coatings. This was applied to the Global Precipitation Measurement core spacecraft. In order to assess the validity of this process, this work applies the similar process to the Lunar Reconnaissance Orbiter. A flight-correlated thermal model was exercised to give predictions of the thermal performance over the mission life. These results were then compared against flight data from the first two years of the spacecraft's use. This is used to validate the process and to suggest possible improvements for future analyses.
\end{abstract}

\section{Nomenclature}

$\begin{array}{ll}\text { BOL } & =\text { Beginning of Life } \\ C B E & =\text { Current Best Estimate } \\ C R a T E R & =\text { Cosmic Ray Telescope for the Effects of Radiation } \\ E O L & =\text { End of Life } \\ F P & =\text { Focal Plane } \\ G M M & =\text { Geometric Math Model } \\ G S F C & =\text { Goddard Space Flight Center } \\ H G A S & =\text { High Gain Antenna System } \\ \text { IR } & =\text { Infrared } \\ I T P & =\text { Isothermal Panel } \\ \text { LLO } & =\text { Low Lunar Orbit } \\ \text { LOLA } & =\text { Lunar Orbiter Laser Altimeter } \\ \text { LRO } & =\text { Lunar Reconnaissance Orbiter } \\ \text { LROC } & =\text { Lunar Reconnaissance Orbiter Camera } \\ M E B & =\text { Main Electronics Box } \\ N A C & =\text { Narrow Angle Camera } \\ N A S A & =\text { National Aeronautics and Space Administration } \\ O S R & =\text { Optical Solar Reflectors }\end{array}$

\section{Introduction}

TANDARD bounding case thermal analysis uses stacked worst-case assumptions such as environmental heat loads and coatings degradation to predict the absolute minimum and maximum temperatures expected for a component. Although this can be useful in design, it does not tell the responsible engineers how much time is spent near the limits and when that might occur. If that information were available, the engineering team would be capable of deciding whether it is worth designing for all bounding cases, or whether it is acceptable to take a risk on some cases that might only represent a small fraction of the actual mission timeline. In response to this, a lifetime thermal analysis method was developed for the Global Precipitation Measurement (GPM) mission (Peabody and Benitez, 2012). This paper attempts to validate that approach by applying it to the Lunar Reconnaissance Orbiter (LRO) thermal analysis and compare it to flight temperature measurements. 
LRO is a NASA GSFC-led mission to provide a detailed map of Earth's moon. It was launched in June of 2009 into a polar low lunar orbit (LLO), where it has been operating since. It is nadir-pointing, and performs a yaw-flip at a zero degree beta angle, allowing the thermal system to be designed for beta ranges of $0^{\circ}$ to $90^{\circ}$.

\section{LRO Thermal Design Overview}

The LRO thermal design was heavily driven by the extreme thermal environments seen at the moon. In addition to the standard solar fluxes, the lunar surface has a very low albedo of 0.05 to 0.13 . This results in a large surface IR that varies largely as a function of the distance between the nadir point and the sub-solar point. These design environments are shown in Figure 1 (Baker, 2009). This large surface IR load drives most large radiators to the zenith surface, where they can receive direct solar loads, which in turn drives the need for radiator coatings with low solar absorptivity. Lower-power radiators were put on a permanently-shadowed side of the spacecraft, but were then made sensitive to glancing views of this large surface IR loads.

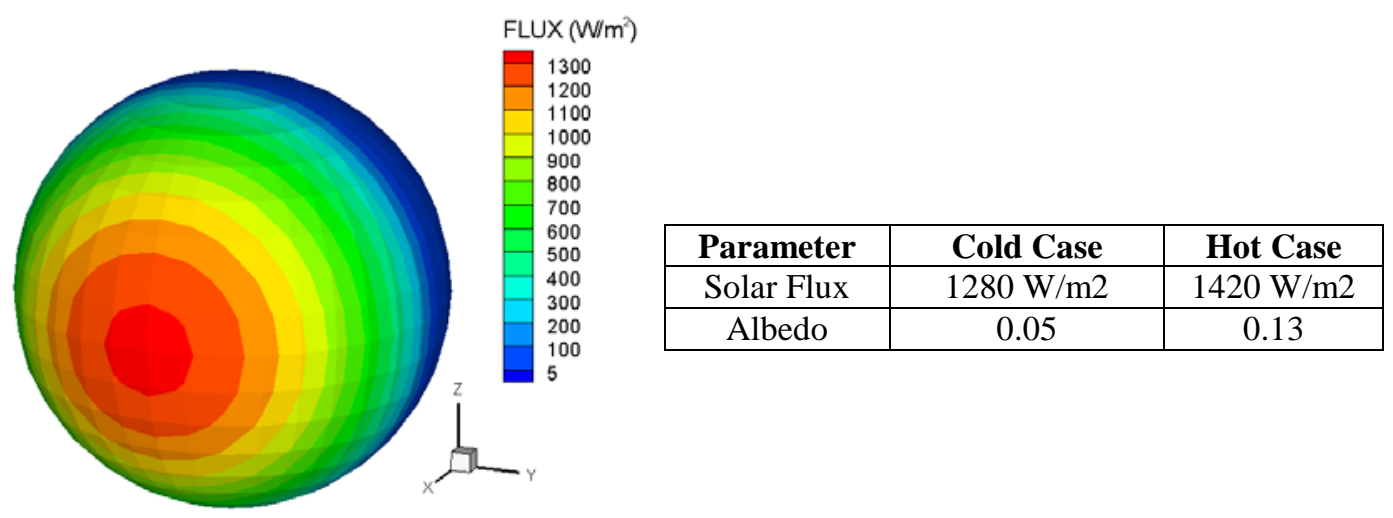

Figure 1 Lunar Thermal Environments

LRO consists of many different thermal control points, but this study is limited to a subset that represents the variety of zones available. These referenced components are shown in Figure 2 and described in Table 1. All of the components here include both operational and survival heater circuits.

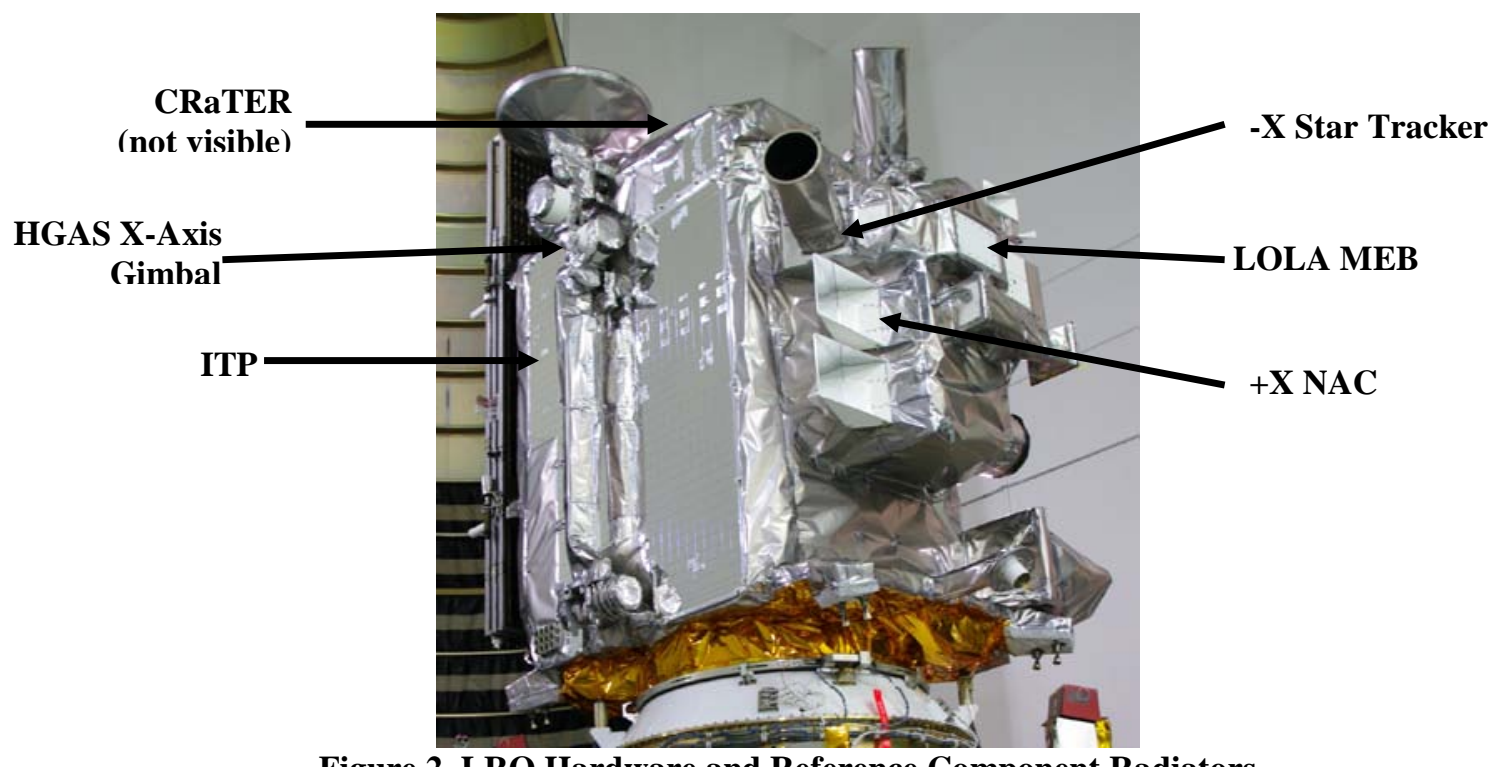

Figure 2. LRO Hardware and Reference Component Radiators

Table 1. Referenced Components Descriptions 


\begin{tabular}{|l|l|l|l|l|}
\hline \multicolumn{1}{|c|}{ Component } & \multicolumn{1}{|c|}{ Description } & \multicolumn{1}{|c|}{$\begin{array}{c}\text { Radiator } \\
\text { Coating }\end{array}$} & Solar Exposure & \multicolumn{1}{|c|}{$\begin{array}{l}\text { Lunar IR } \\
\text { Exposure }\end{array}$} \\
\hline $\begin{array}{l}\text { ITP Header Heat } \\
\text { Pipe }\end{array}$ & $\begin{array}{l}\text { Heat pipe network transports heat } \\
\text { from all avionics to a zenith radiator }\end{array}$ & OSR & $\begin{array}{l}\text { Direct at low } \\
\text { beta angles }\end{array}$ & None \\
\hline -X Star Tracker & $\begin{array}{l}\text { The }- \text { X tracker is mounted to a } \\
\text { dedicated radiator }\end{array}$ & $\begin{array}{l}\text { Z93 White } \\
\text { Paint }\end{array}$ & $\begin{array}{l}\text { Direct at low } \\
\text { beta angles }\end{array}$ & None \\
\hline $\begin{array}{l}\text { HGAS X-Axis } \\
\text { Gimbal }\end{array}$ & $\begin{array}{l}\text { Actuator radiator has different views } \\
\text { to the sun, the lunar surface and deep } \\
\text { space depending on dish orientation }\end{array}$ & $\begin{array}{l}\text { Z93 White } \\
\text { Paint }\end{array}$ & $\begin{array}{l}\text { Direct depending } \\
\text { on dish } \\
\text { shadowing }\end{array}$ & $\begin{array}{l}\text { Depending on } \\
\text { dish shadowing }\end{array}$ \\
\hline $\begin{array}{l}\text { +X LROC NAC } \\
\text { FP }\end{array}$ & $\begin{array}{l}\text { Instrument radiator has a specular } \\
\text { reflective shield to eliminate direct } \\
\text { solar loads and limit lunar surface } \\
\text { loads }\end{array}$ & $\begin{array}{l}\text { Z93 White } \\
\text { Paint }\end{array}$ & $\begin{array}{l}\text { Albedo only, } \\
\text { limited by shield }\end{array}$ & $\begin{array}{l}\text { Limited by } \\
\text { shield }\end{array}$ \\
\hline LOLA MEB & $\begin{array}{l}\text { Instrument electronics box with an } \\
\text { integrated radiator }\end{array}$ & $\begin{array}{l}\text { Z93 White } \\
\text { Paint }\end{array}$ & Albedo only & Yes \\
\hline CRaTER Radiator & $\begin{array}{l}\text { Instrument is mounted to a dedicated } \\
\text { radiator that has substantial views to } \\
\text { MLI }\end{array}$ & OSR & $\begin{array}{l}\text { Direct at low } \\
\text { beta angles }\end{array}$ & None \\
\hline
\end{tabular}

\section{Lifecycle Analysis Method}

Typical bounding thermal analysis using worst-case beta angles, environmental heat sources and coating degradations is an efficient way to show minimum margins for a given design. However, it does not give a sense of the actual temperature margin expected throughout the mission, or how frequently limit violations may occur. For instance, a systems team may buy-off on a limit violation if it is only expected to occur for 2 weeks out of a 5 year mission, especially if the re-design to fix the predicted violation is deemed too costly.

The lifecycle analysis method was put together in an attempt to solve this problem for the Global Precipitation Measurement (GPM) mission (Peabody and Benitez, 2012). In this process, the thermal model was run with all possible combinations of input variables:

- Thermal-optical coatings degradation (EOL and BOL)

- Thermal environments (hot and cold)

- Beta angle $\left(0^{\circ}, 10^{\circ}, 20^{\circ}, 30^{\circ}, 40^{\circ}, 50^{\circ}, 60^{\circ}, 70^{\circ}, 80^{\circ}\right.$ and $\left.90^{\circ}\right)$

The resulting 40 thermal cases were then loaded into a spreadsheet and linearly interpolated into a 3-dimensional solution space for those variables. The predicted mission profile of days since launch, day of year and beta angle was then loaded into the database as a reference point.

The mission profile was converted into environmental inputs using the following assumptions. The predicted beta angle does not require any translation in order to be used in this lifecycle analysis method.

1. The thermal-optical properties degrade in a linear manner over the course of the designed mission life.

2. The environment varies linearly with respect to the distance to the sun, with hot environments occurring at perihelion and cold environments at apohelion. This means that environments vary in a sinusoidal manner versus the day of the year, with the hottest environment on January $3^{\text {rd }}$ and the coldest on July $4^{\text {th }}$.

Once the state of the coatings degradation, the thermal environment and the beta angle are known for each point in time, the linear interpolation can be carried out in a staged fashion: first on beta angle, then thermal environment, and finally on coatings degradation. The order of these operations does not matter, but it was determined that interpolating on beta angle reduced the number of calculations since beta angle has 10 points, only 2 of which are applicable for each case. This allows $80 \%$ of the data points to be ignored in the interpolations. An example calculation in shown in Figure 3. For the sake of simplicity, BOL coatings are given a value of 0 and EOL coatings are given a value of 1 ; likewise cold environments are also given a value of 0 and hot environments are 1 . 


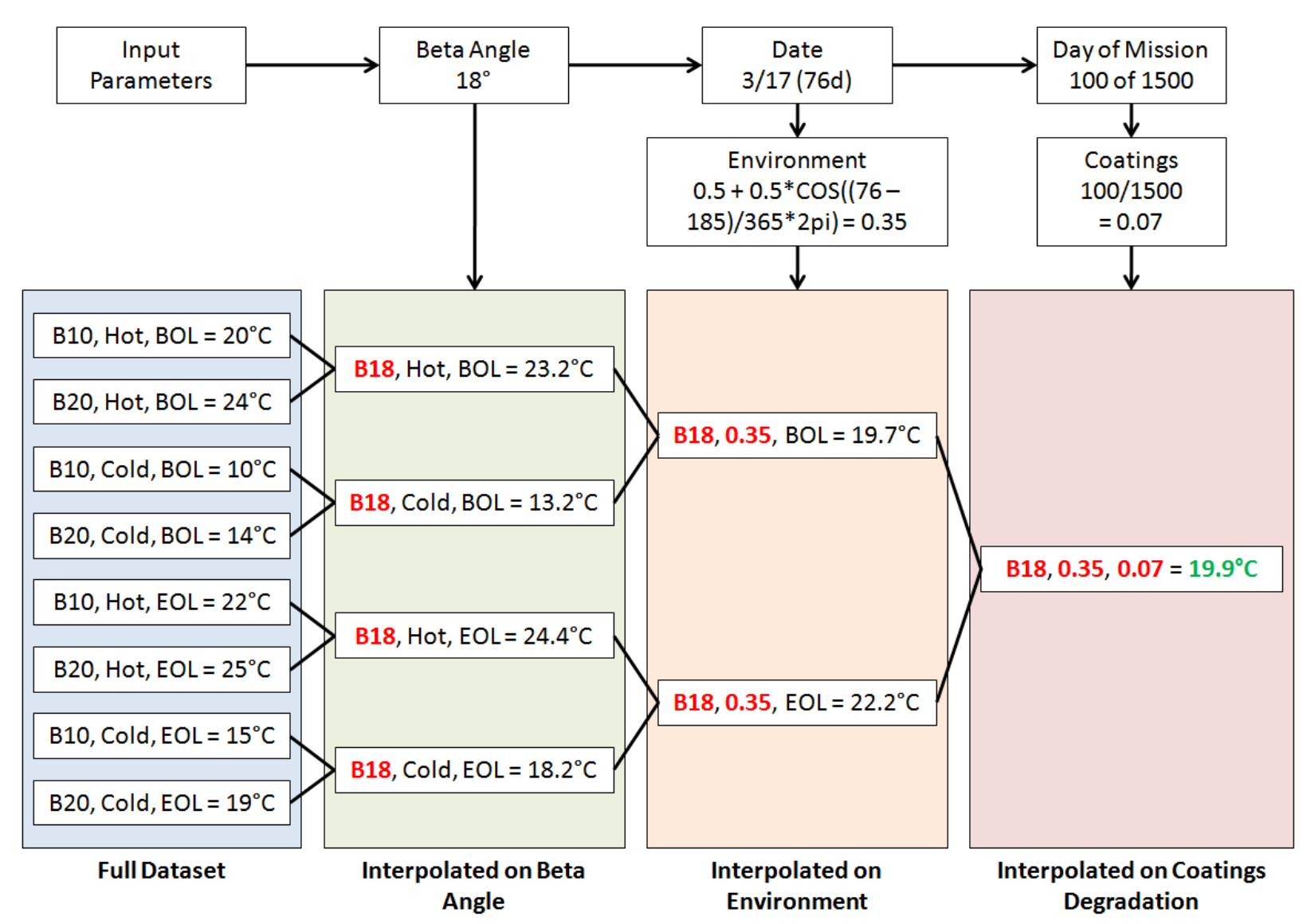

Figure 3. Sample Interpolation for a Given Set of Inputs

This method was applied to the GPM thermal model to give predicted margins on each major component throughout the mission. However, the process was never validated against a project with existing flight data. The following sections will show the results of this process for the LRO thermal model and will show its comparison against flight telemetry.

\section{LRO Mission Life Predictions - Trend Investigations}

Prior to running the full mission life predictions for the LRO model, some exploratory runs were completed to determine if the planned interpolation would be sufficient to replicate the full solution space. In order to determine this for the coatings degradation, the BOL and EOL cases were run and averaged, which gives the linear interpolation of a half-life properties. This was compared against a separate run using optical properties that were half-way between the BOL and EOL values. The error between the real analysis and the interpolated value averaged $0.1^{\circ} \mathrm{C}$, with the worst error on the ITP $\left(0.4^{\circ} \mathrm{C}\right)$. It was determined that these errors were small enough to allow linear interpolation on the optical property degradation.

A similar study was done with the hot case environments, cold case environments, and a set of environments half-way between the two extremes. In this case, the error between the direct solution and the interpolated value was an average of $0.3^{\circ} \mathrm{C}$, with the worst errors on the LOLA MEB $\left(0.8^{\circ} \mathrm{C}\right)$. Again, it was determined that the error was acceptable to allow interpolation on the environment.

Finally, the different beta angles investigated were analyzed to see if they could be fit with a standard 3, 4, or 5 term polynomial to reduce the number of cases that had to be run, since each beta angle eliminated would reduce the total number of SINDA runs by 4 . However, the different components each exhibited different shaped beta-versustemperature curves, as exhibited in the ITP and ST plots in Figure 4. These shapes are affected by both geometry (shadowing, reflections, etc) and the presence of heaters. A linear interpolation of every 20 degrees of beta angle instead of every 10 yielded errors up to $2.8^{\circ} \mathrm{C}$, which was determined to be unacceptable. Based on this, it was determined to stay with the baseline of every 10 degrees of beta angle. 


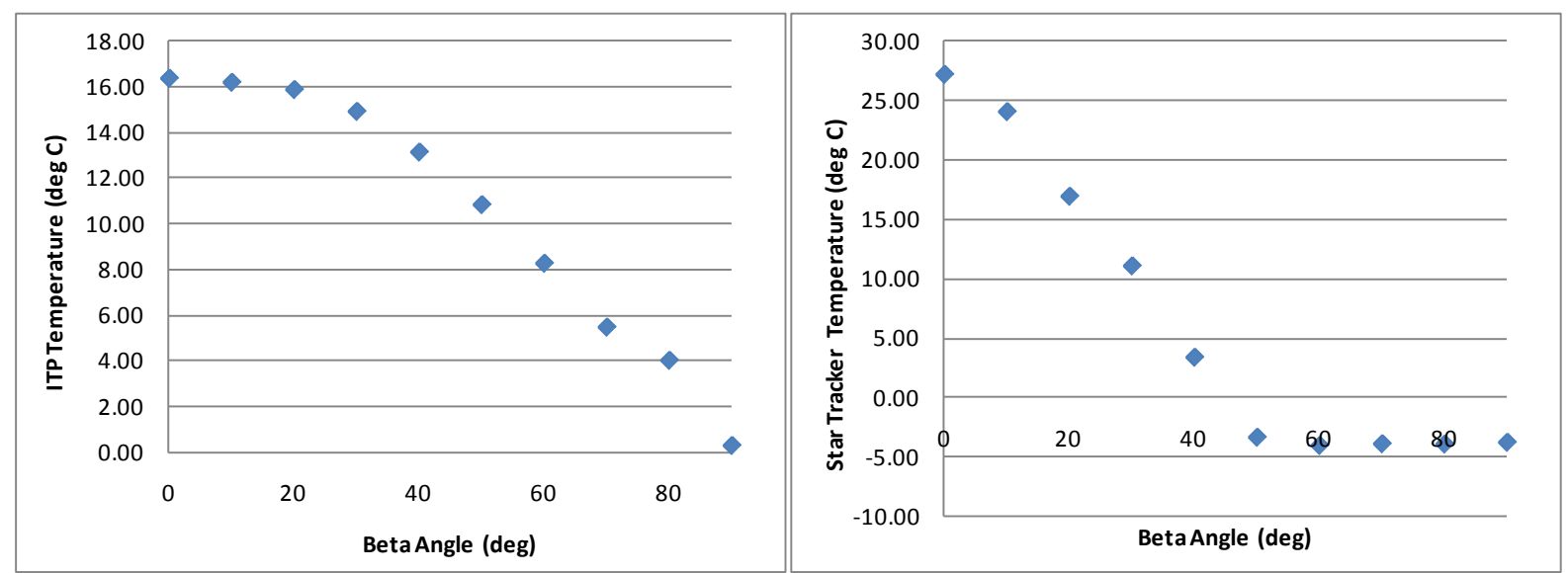

Figure 4. Temperature Dependence on Beta Angle for ITP and ST

\section{LRO Mission Life Predictions - Baseline Assumptions}

The LRO operations team provided a data set consisting of the date and beta angle for the first 536 days of the orbiter's mission, which was input into the analysis database. This was used to calculate a predicted orbit-maximum temperature for each component each day, which was then plotted against the actual measured telemetry. All of these components had been correlated to within $2^{\circ} \mathrm{C}$ of observed temperatures during observatory thermal balance testing, so errors could be at least that large even if the methodology and assumptions are perfect.

The resulting predictions are plotted against the flight data and the bounding hot prediction for each of the six components, and the error between the prediction and flight data, in Figures 5-10. For ease of comparison, a 5-day moving average line has been added to the error plots. Note that there are occasional short-term temperature changes that reflect non-standard operations, such as the lunar eclipse pre-heat on the ITP around day 450 or instrument turnoff events around day 150. Errors during these events can be ignored since they do not reflect on the model's capability.
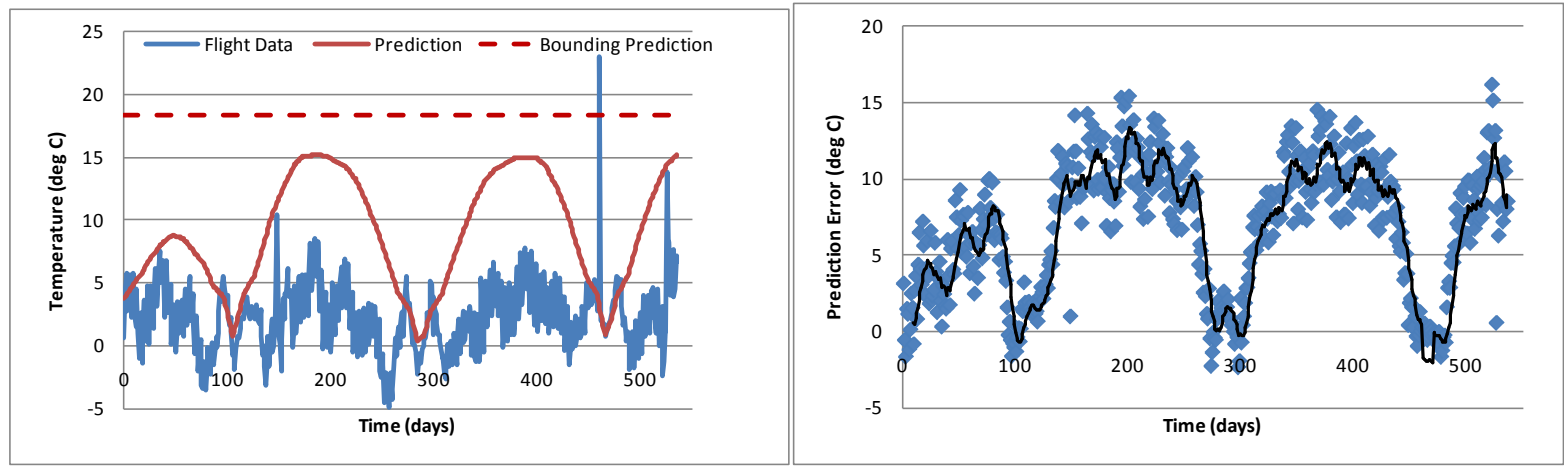

Figure 5. ITP Temperature Predictions and Error Versus Flight 

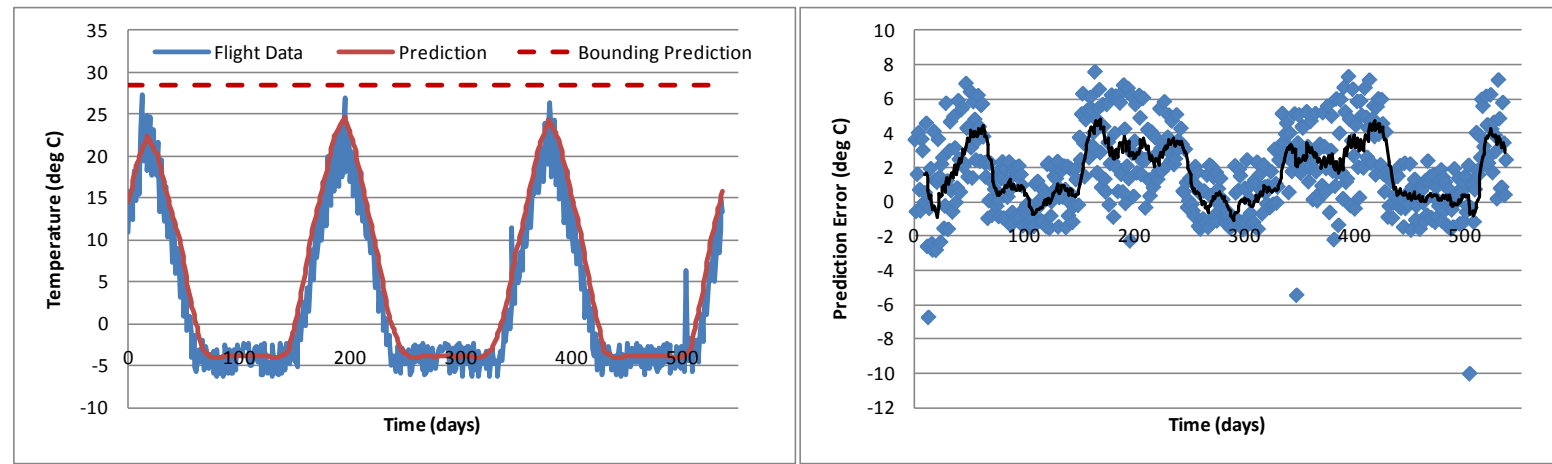

Figure 6. ST Temperature Predictions and Error Versus Flight
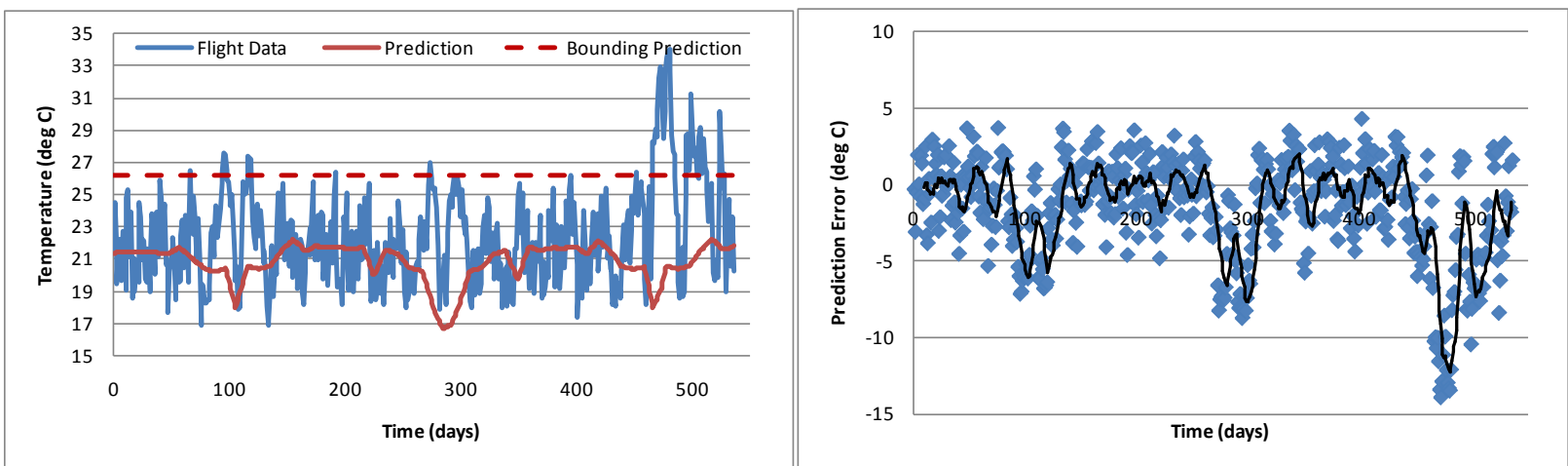

Figure 7. HGAS Temperature Predictions and Error Versus Flight
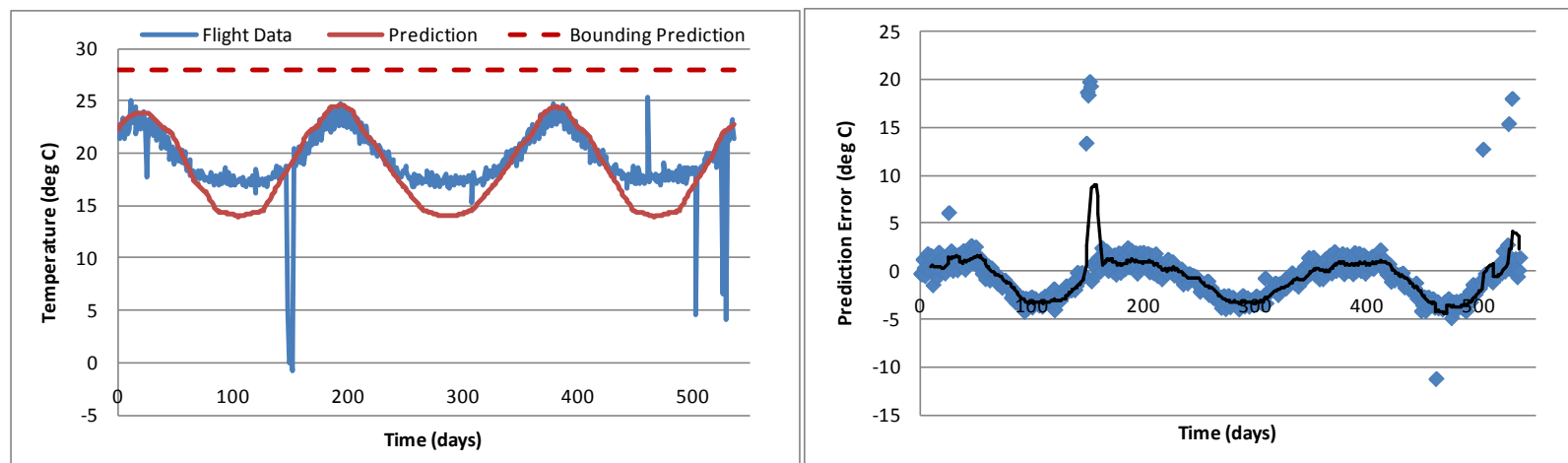

Figure 8. LROC Temperature Predictions and Error Versus Flight

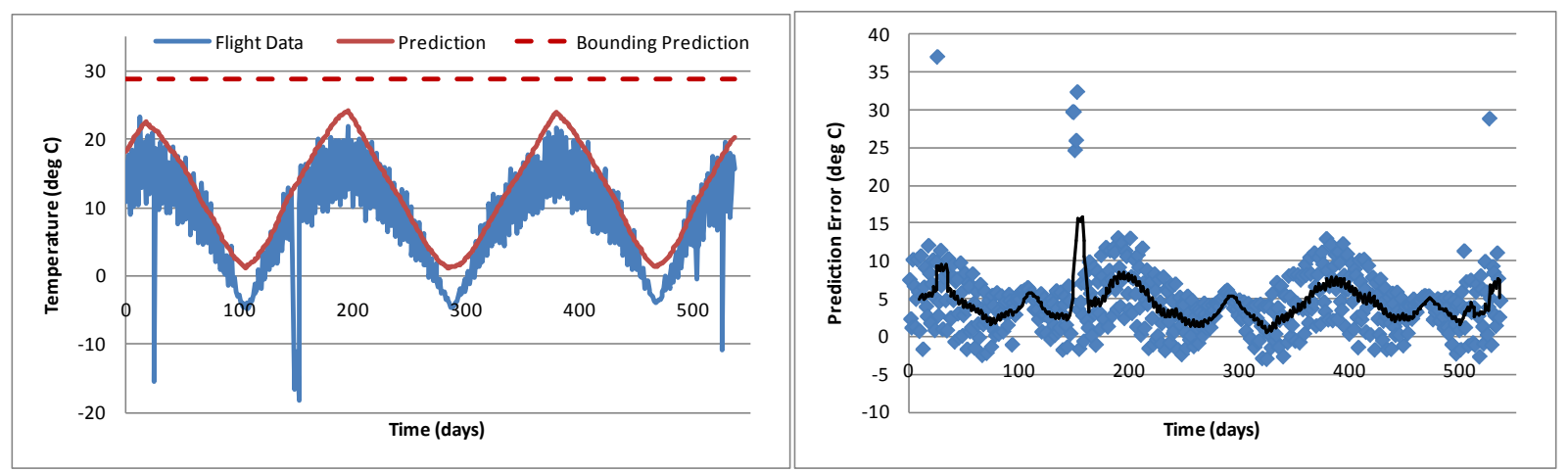

Figure 9. LOLA Temperature Predictions and Error Versus Flight

6

American Institute of Aeronautics and Astronautics 


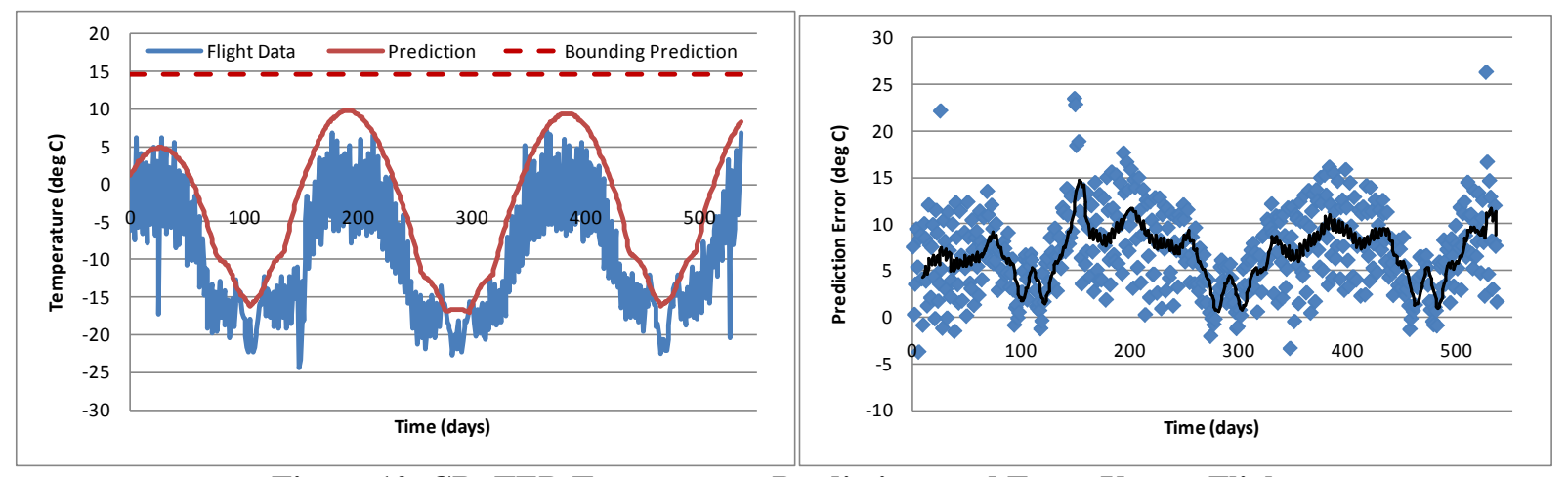

Figure 10. CRaTER Temperature Predictions and Error Versus Flight

Based on these plots, multiple conclusions can be reached:

1. The ITP, HGAS, LOLA and CRaTER flight temperatures are all very noisy, indicating that there is some short-term transient influencing the temperature that is not covered in this analysis. For the ITP, this is likely fluctuations in the total avionics power. Electronics power dissipations can vary depending on the state of the spacecraft and what tasks are being performed, and this is not captured in the thermal model. For the HGAS, it is likely different antenna orientations not captured in the GMM.

2. The ITP and CRaTER temperature predictions are almost constantly above the flight measured temperature, and this error is higher at higher beta angles (day 200 and 400) when the radiators flash directly through the sun. This indicates that the solar loading on the OSR radiators is lower than predicted, either due to a lower solar flux or a lower OSR absorptivity or both. This can be seen in Figure 11, which shows the flight temperatures of the ITP and CRaTER closely matching the cold environment, BOL coatings case when plotted against beta angle. A similar trend can be seen for LOLA, LROC and ST, but they are less severe because they see less solar loading.
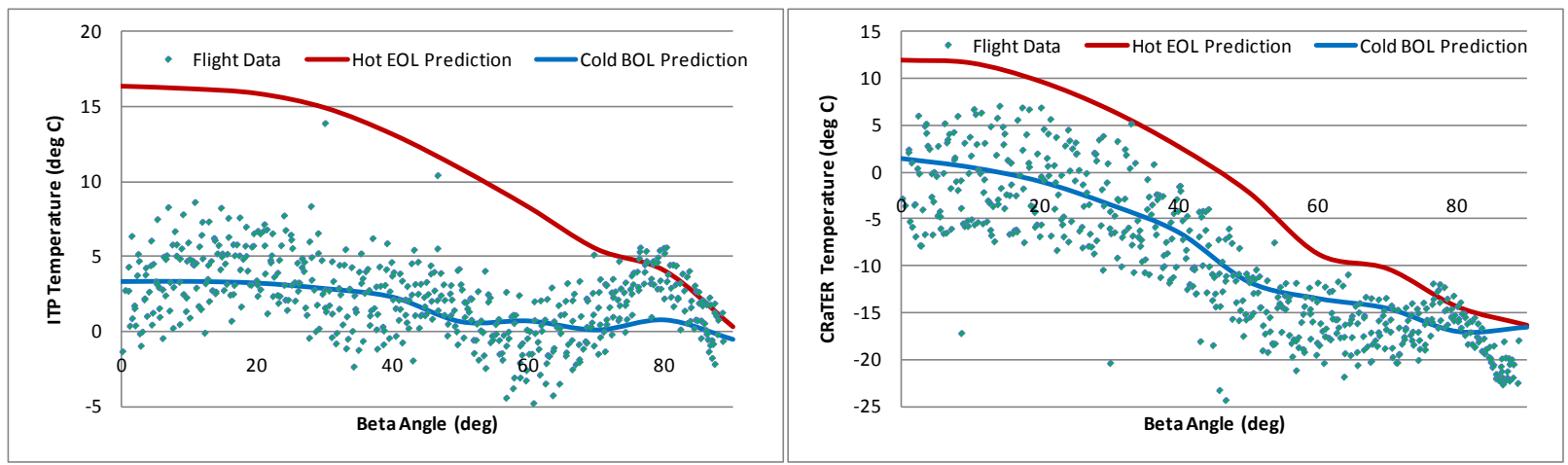

Figure 11. ITP and CRaTER Temperatures Correlated to Beta Angle

3. The HGAS actuators are continuously operating on their heater, which turns off at $22^{\circ} \mathrm{C}$, with small warm excursions due to unmodeled sun views. That essentially makes the HGAS actuators useless in validating this analysis approach.

4. All flight temperatures seem to be repeatable over the entire 536 days. Since all parameters are repeating except for the coatings degradation, this suggests that the coatings themselves are remaining stable.

5. Most flight data is at least $10^{\circ} \mathrm{C}$ below the bounding hot-case prediction, indicating that the thermal model has effectively bounded the flight data without adding modeling uncertainty. The only exception to this is the HGAS actuator. This is reflected in previous work (Garrison, 2011).

6. None of the lifecycle thermal analysis predictions shown in Figures 5-10 actually reached the bounding thermal analysis predictions. All of these components (except for the HGAS) had their hottest bounding predictions in a 0 degree beta angle orbit. The bounding cases also assumed EOL coating degradations and the hottest environmental heat loads. However, as Figure 12 shows, these cases never occurred. This means that the entire thermal system was sized for a case that the spacecraft has not seen, although it is a possible combination that may eventually arise beyond the planned 1-year mission life. Likewise, 
although it is not discussed here, the worst-case cold conditions (90 degree beta angle, BOL optical properties and cold environments) also never occurs.

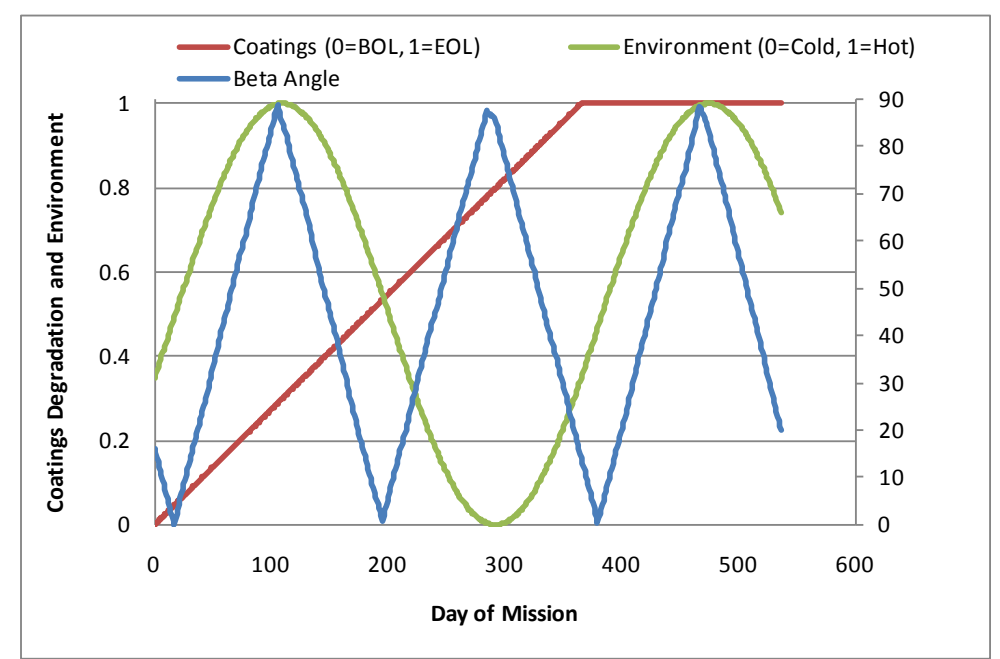

Figure 12. Observed Orbital Conditions for LRO

\section{LRO Mission Life Predictions - Updated Assumptions}

Based on the conclusions discussed in the previous section, some of the parameters in the lifecycle analysis were adjusted and the results were re-calculated. Based on conclusion 2, the coatings were set to always be in a BOL condition. However, further gains were realized by keeping the environments constant as shown in Table 2. Constant environmental heat loads can be justified because the dominant sources are solar and lunar IR, which is directly solved from the solar loading. Solar intensity varies by $~ 1 \%$ between perihelion and apohelion, which does not justify the $10 \%$ variation used in the baseline analysis cases. Instead, we are suggesting a constant solar load of $1315 \mathrm{~W} / \mathrm{m}^{2}$, which works out to a value $25 \%$ of the way from the cold value to the hot value. This shows that the vast majority of the gains in accuracy can be gained by assuming that the optical properties have not degraded over the 536 days of the mission, especially on the OSR radiators (ITP and CRaTER). Controlling the environment reduces the error by an additional $0-10 \%$ beyond the gains from the optical property conclusion.

Table 2. Comparison of Errors Between Baseline and Updated Assumptions

\begin{tabular}{|c|c|c|c|}
\hline Component & $\begin{array}{c}\text { Average Error } \\
\text { Magnitude, Baseline } \\
\text { Assumptions }\end{array}$ & $\begin{array}{c}\text { Average Error Magnitude, } \\
\text { Always BOL and Baseline } \\
\text { Varying Environment }\end{array}$ & $\begin{array}{c}\text { Average Error Magnitude, } \\
\text { Always BOL and 25\% } \\
\text { Environment }\end{array}$ \\
\hline ITP Header Heat Pipe & $7.0^{\circ} \mathrm{C}$ & $1.8^{\circ} \mathrm{C}$ & $1.8^{\circ} \mathrm{C}$ \\
\hline -X Star Tracker & $2.2^{\circ} \mathrm{C}$ & $1.9^{\circ} \mathrm{C}$ & $1.7^{\circ} \mathrm{C}$ \\
\hline HGAS X-Axis Gimbal & $2.7^{\circ} \mathrm{C}$ & $2.9^{\circ} \mathrm{C}$ & $2.7^{\circ} \mathrm{C}$ \\
\hline +X LROC NAC FP & $1.8^{\circ} \mathrm{C}$ & $2.0^{\circ} \mathrm{C}$ & $1.8^{\circ} \mathrm{C}$ \\
\hline LOLA MEB & $4.7^{\circ} \mathrm{C}$ & $4.1^{\circ} \mathrm{C}$ & $3.8^{\circ} \mathrm{C}$ \\
\hline CRaTER Radiator & $6.9^{\circ} \mathrm{C}$ & $4.0^{\circ} \mathrm{C}$ & $3.6^{\circ} \mathrm{C}$ \\
\hline
\end{tabular}

\section{Conclusions}

The work presented in this paper shows that lifecycle thermal analysis method developed for the GPM project can accurately predict the temperatures over a spacecraft's mission lifetime when appropriate assumptions are made. However, this is an expensive analysis. In order to set up and run all of the analysis, including radiation couplings, heat rates, SINDA and post-processing, it took approximately 4 full days of analyst time and 2 weeks of computation on a mobile workstation. However, as cluster computing becomes more prevalent, thermal software becomes more parameterized, and the process is more frequently preformed, the expected man-in-the-loop hours could be reduced considerably. At this point it time, it is not a good design tool for frequent use, but can be used sparingly to provide more in-depth temperature predictions as part of a major design cycle. 
It is also possible to draw some conclusions about the LRO thermal analysis based on the comparisons shown here. It appears that the coatings did not degrade at all over the first 536 days of the LRO mission. Also, the environmental heat loads did not appear to be as severe as was predicted. Both of these incorrect assumptions have led to LRO being over-designed.

Finally, it is evident that the stacked worst-case conditions for LRO never actually existed, despite that being the driving design case. It is recommended that future missions run a similar analysis early in their design cycle, preferably before their preliminary design reviews, to verify that their worst cases are actually expected to occur.

\section{Acknowledgements}

The primary author (Matt Garrison) would like to thank the LRO thermal and operational teams, which provided both the flight data and the thermal model used for this study. He would also like to thank Hume Peabody and Veronica Benitez for developing the lifecycle thermal analysis method. Without both of these contributions, this study would not be possible.

\section{References}

Baker, C., et al, "Lunar Reconnaissance Orbiter Rapid Thermal Design Development," International Two-Phase Thermal Control Technology Workshop, El Segundo, CA, October 2009.

Garrison, M. "Statistical Analysis of Thermal Analysis Margin,” Thermal and Fluids Analysis Workshop, Newport News, VA, August 2011.

Peabody, H. \& Benitez, V. "Thermal Margin Study for the Global Precipitation Measurement Spacecraft." $42^{\text {nd }}$ International Conference on Environmental Systems, San Diego, CA, July 2012. 